\title{
Hepatoprotective activity of Cuscuta reflexa aqueous and alcoholic extracts against CCl4 induced toxicity in rats
}

\author{
RANJAN Rakesh ${ }^{1 *}$, KUMAR Manoj ${ }^{1}$, KUMAR Amar $^{2}$, SINHA Manoranjan Prasad ${ }^{1}$
}

Corresponding author: Rakesh Ranjan: E-mail: rakeshranjanla108@gmail.com, $\underline{\text { dr17mk@gmail.com }}$

\begin{abstract}
Introduction In the present study the impact of aqueous and alcoholic extracts of Cuscuta reflexa were investigated on rats intoxicated with carbon tetrachloride $\left(\mathrm{CCl}_{4}\right)$. $\mathrm{CCl}_{4}$ is known to intoxicate the liver of rats which can be easily be observed by examining the total protein, total bilirubin, alkaline phosphatase (ALP), aspartate aminotransferase (AST), alanine transaminase ALT). Cuscuta reflexa have been used in traditional medicine culture from time immemorial. In this study both the aqueous and alcoholic extracts of Cuscuta reflexa were found to have curative impact on liver profile of $\mathrm{CCl}_{4}$ intoxicated rats.

Materials and Methods. The stem of Cuscuta reflexa were collected from host bougainvillea, dried in shade and were subjected to alcoholic (ethanolic), and aqueous extraction. Albino rats were intoxicated with $\mathbf{C C l}_{4}$ to induce hepatotoxicity. The $\mathbf{C C l}_{4}$ intoxicated rats were treated with low dose and high dose of both the extracts to assess the hepatoprotective impact on intoxicated rats. The results clearly revealed that the $\mathbf{C C l}_{4}$ administration altered liver profile. The altered liver profile parameters recovered to normal after administration of aqueous and alcoholic extracts.

Results and Discussion. Administration of $\mathbf{C C l}_{4}$ induced hepatotoxicity in albino rats, which was evident with the results of serum analysis. Post $\mathbf{C C l}_{\mathbf{4}}$ administration the liver profile parameters were altered. The $\mathbf{C C l}_{\mathbf{4}}$ intoxicated rats were then treated with aqueous and alcoholic extracts of Cuscuta reflexa. Post treatment with the extracts the liver profile parameters recovered to normal. Conclusion: Present study reveals that aqueous and alcoholic extracts of Cuscuta reflexa were found to have curative impact on liver profile of $\mathbf{C C l}_{4}$ intoxicated rats.
\end{abstract}

Keywords: Custuca reflexa, $\mathrm{CCl}_{4}$, hepatoprotective, liver profile, alcoholic extract, aqueous extract,

\section{Introduction}

Herbal medicines are in great demand in the developing world for primary health care (1). But slowly the herbal medicines are also gaining grounds in the developed countries because herbal medicines have been reported to be as effective as their conventional counterparts $(2,3)$. The plant drugs constitute about $25 \%$ of total drugs in United States, while in developing countries such as China and India, the contribution is as much as $80 \%$. The contribution of plants is remarkable in diversified industries such as fine chemicals, cosmetics, pharmaceuticals and drugs and industrial raw materials etc. Medicinal plants have been playing sole role in coping with a number of deadly diseases including cancer and diseases associated with viral onslaught (4). There are innumerable of medicinal plants which are being used since time immemorial as medicines, one of them is Cuscuta reflexa. Cuscuta reflexa is a parasitic plant belonging to family Convolvulaceae, is commonly known as amarbel, akashbel. Traditionally it is called as miracle plant. The plant is rootless, perennial, leafless climbing parasitic, twining herb, it obtains food from varieties of host plants using specialized organ called haustorium (5). Cuscuta reflexa does not have any references in vedic and Samhita kala, but it is well defined in Nighantus such as Bhavprakash Nighantu, Raj Nighantu, Adarsh Nighantu, Shankar Nighantu and Madanpal Nighantu. The extract of Cuscuta reflexa is traditionally used to cure jaundice, gout, body aches, constipation, flatulence, liver disorders (5). Owing to the above information about Cuscuta reflexa, the present work was undertaken to establish firsthand knowledge regarding the use of aqueous and alcoholic extracts of Cuscuta reflexa as hepatoprotective agent. There are information regarding use of Cuscuta reflexa extracts in case of jaundice and liver related ailments, but nothing has been scientifically established.

\section{Materials and Methods}

\section{Plant Materials}

Cuscuta reflexa stems were collected from bougainvillea (host). The stems were washed with water and disinfected with $0.1 \% \mathrm{HgCl}_{2}$ solution for $5 \mathrm{~min}$ and dried in shade away from direct light for 20 days and ground to fine powder using electrical grinder. The powder obtained was sieved and stored in air-tight containers for future use (6).

\section{Preparation of Extracts}

The fine powder of Cuscuta reflexa was made into thimble for loading in Soxhlet apparatus and extraction was done using distilled water for aqueous extract and ethanol for alcoholic extract. The extraction was continuously done for 72 hours. The extracts thus obtained were concentrated in vacuum rotary evaporator and extracts were kept in desiccators until used (7).

\section{Phytochemical Screening}

Preliminary phytochemical screenings were conducted on Cuscuta reflexa aqueous and alcoholic extract in accordance to previously published standards (8).

\section{Animals}


Albino rats weighing about 175-200 $\mathrm{g}$ were used in the study. They were maintained under standard laboratory conditions at ambient temperature of $25 \pm 2{ }^{\circ} \mathrm{C}$ and relative humidity at $50 \pm 15 \%$ with dark-light cycle of $12 \mathrm{~h}$. Animals were fed with a commercial pellet diet and water ad libitum. The experiment was performed after prior approval of Ethics committee of Ranchi University, Ranchi (Proceeding no. 46, Page no. 137).

\section{Acute Toxicity Study}

The acute oral toxicity of both alcoholic and aqueous extracts was determined following OECD guidelines 423 (9). It is the principle of the test to reduce and use minimum possible number of animals. The substances (extracts) were administered orally to a group of animals at one of the defined doses. The substance was tested using a step wise procedure, each step using three animals of single sex (normally females). The absence of substance-related mortality of the animals dosed at one step determined the next step. A total of 15 healthy adult albino rats weighing about $175-200 \mathrm{~g}$ and 8-12 weeks old were used in the study. Females were nulliparous and non-pregnant. The rats were fasted overnight prior to dosing. After dosing, food was withheld for 3-4 hours. Three animals were used in each step, since nothing was known about the toxic level of the substance in rats; the starting dose was selected as minimum ( $5 \mathrm{mg} / \mathrm{kg}$ body weight). The substances were administered in single dose by using oral gavage. Animals were observed individually after dosing, at least once for first 30 minutes, periodically during first hour, with special attention during first 4 hours and daily thereafter, for a total of 14 days. However, the duration of observation was not fixed rigidly, i.e. dosed animals were caged separately post 14 days' observation and observed for next 14 days. No mortality was observed up to a dose of $2000 \mathrm{mg} / \mathrm{kg}$ of body weight of rats (Kumar M., 2020) (10).

\section{Research Design}

The animals were divided into 6 groups. The group 1 consisted of 3 rats, this group served as control and the rats were treated with distilled water orally for 7 days. Post 7 days, the blood samples were collected following the orbital sinus blood sample collection method (11). Group 2 consisted of 12 rats, the rats in this group were treated with solution of $\mathrm{CCl}_{4}$ orally for seven days. after 7 days blood samples were collected from the rats to see the impact of $\mathrm{CCl}_{4}$ administration in rats. The data was recorded and then the rats were divided into 4 groups (Group 3, Group 4, Group 5 and Group 6) which respectively received low doses and high doses of both aqueous and alcoholic extracts of Cuscuta reflexa for 14 days. Post 14 days of administration of the rats with extracts of Cuscuta reflexa. The blood samples were again collected and analyzed to study the impact of extracts on the hepatic profile of $\mathrm{CCl}_{4}$ intoxicated rats. The distribution of groups were as follows -

Group 1 (control) - received distilled water orally (3 rats).
Group 2 (test group) - received $\mathrm{CCl}_{4}$ solution orally (12 rats).

Group 3 (AQLD) derived from group 2 - received low dose of aqueous extract orally (3 rats).

Group 4 (AQHD) derived from group 2 - received high dose of aqueous extract orally (3 rats).

Group 5 (ALLD) derived from group 2 - received low dose of alcoholic extract orally (3 rats).

Group 6 (ALHD) derived from group 2 - received high dose of alcoholic extract orally (3 rats).

\section{Results and Discussion}

Phytochemical Screening

The preliminary phytochemical screening showed the presence of aqueous and alcoholic extract of Cuscuta reflexa extracts showed the presence of phytochemicals such as alkaloids, flavonoids, carbohydrates, glycosides, phytosterols, phenolics, tannins and saponins. The phytochemicals are naturally occurring compounds in plant foods, have been reported to provide various biological functions in humans (12). Raj et al. (2010) (13) reported that the alkaloid fractions derived from Hygrophila auriculata leaves posed hepatoprotective activity against $\mathrm{CCl}_{4}$ induced toxicity in rats. Sawi and Sleem (2010) (14) concluded that the hepatoprotective activity of extracts of Senna surattensis may be due to the free radical scavenging activity posed due to the antioxidant activity of flavonoids present in the extract. The terpenoids (15), saponins (16), phenolics (17), tannins (18) have also been reported to possess antioxidant and hepatoprotective activity in plant extracts possessing them.

Table 1: results of preliminary phytochemical screening of aqueous and alcoholic extracts of Cuscuta reflexa

\begin{tabular}{|l|l|l|}
\hline Phytochemicals & $\begin{array}{l}\text { Presence/absence } \\
\text { in aqueous extract } \\
\text { of Cuscuta reflexa }\end{array}$ & $\begin{array}{l}\text { Presence/absence } \\
\text { in alcoholic } \\
\text { extract of Cuscuta } \\
\text { reflexa }\end{array}$ \\
\hline Alkaloids & - & + \\
\hline Flavonoids & + & + \\
\hline Terpenoids & + & + \\
\hline Saponins & - & - \\
\hline Phenolics & + & + \\
\hline Tannins & + & + \\
\hline
\end{tabular}

\section{Total Bilirubin}

The result of impact of aqueous and alcoholic extract of Cuscuta reflexa is graphically presented as figure 1 . The bilirubin is an endogenous anion derived from haemoglobin degradation from the RBC. Lower than normal bilirubin is usually not a concern, but elevated levels may indicate liver damage or disease (8). The higher level of total bilirubin in the blood indicates that the liver is not clearing bilirubin properly. The result shows that the treatment of $\mathrm{CCl}_{4}$ showed a significant increase in the total bilirubin level, the increased level of total bilirubin level indicates liver damage or dysfunction induced by treatment of $\mathrm{CCl}_{4}$. The rats treated with $\mathrm{CCl}_{4}$ were then treated with low dose and high dose of aqueous and alcoholic extracts of Cuscuta reflexa. The total 
bilirubin level in control rats were $0.52 \pm 0.005 \mathrm{mg} / \mathrm{dl}$, after treatment with $\mathrm{CCl}_{4}$ the total bilirubin was elevated to $0.61 \pm$ $0.02 \mathrm{mg} / \mathrm{dl}$ due to hepatic damage induced by $\mathrm{CCl}_{4}$. The $\mathrm{CCl}_{4}$ intoxicated rats were treated with aqueous and alcoholic extracts of Cuscuta reflexa showed a decrease in the elevated total bilirubin levels which was $0.52 \pm 0.018$ $\mathrm{mg} / \mathrm{dl}, 0.51 \pm 0.05 \mathrm{mg} / \mathrm{l}$ respectively post treatment with low dose and high dose of aqueous extract of Cuscuta reflexa. The total bilirubin level was $0.51 \pm 0.015 \mathrm{mg} / \mathrm{dl}$ and $0.49 \pm$ $0.019 \mathrm{mg} / \mathrm{dl}$ respectively post treatment with low dose and high dose of alcoholic extracts of Cuscuta reflexa.

Figure 1: Impacts of aqueous and alcoholic extract of Cuscuta reflexa on total bilirubin level of albino rats

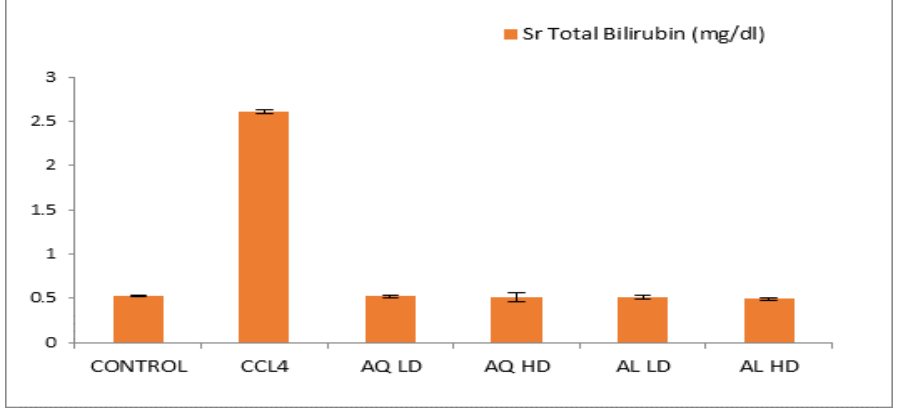

\section{Total Protein}

The total protein test measures the total amount of albumin and globulin in the body. It is used as part of routine health and is also included in liver function tests (LFT). The liver is major source of most of serum proteins. The parenchymal cells are responsible for synthesis of albumin, fibrinogen and other coagulation factors. The total protein test measures the total amount of proteins found in the fluid portion of blood. This test is often done to diagnose liver diseases (10). The result of total protein analysis has been presented as figure 2 .

Figure 2: Impacts of aqueous and alcoholic extract of Cuscuta reflexa on total total protein level of albino rats

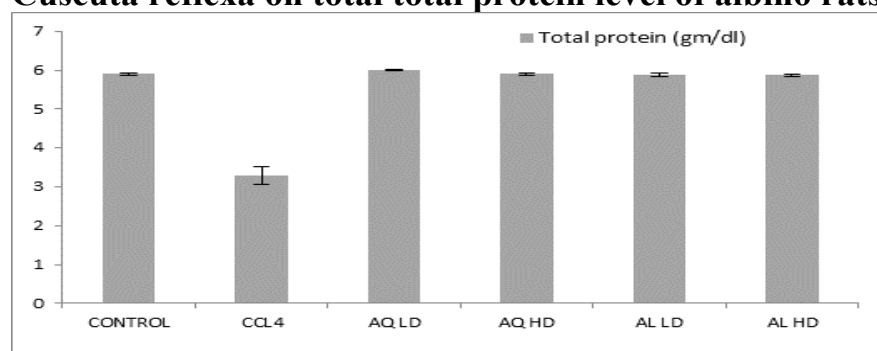

The total protein level in control rats were $5.9 \pm 0.038 \mathrm{gm} / \mathrm{dl}$. The total protein level in $\mathrm{CCl}_{4}$ treated rats decreased to 3.28 $\pm 0.23 \mathrm{gm} / \mathrm{dl}$. The $\mathrm{CCl}_{4}$ intoxicated rats were treated with aqueous and alcoholic extracts of Cuscuta reflexa. Post treatment the total protein level recovered and rose to normal level which was $6.00 \pm 0.02 \mathrm{gm} / \mathrm{dl}$ and $5.9 \pm 0.03 \mathrm{gm} / \mathrm{dl}$ in case of low dose and high dose of aqueous extract of Cuscuta reflexa. In case of alcoholic extract the total protein level in $\mathrm{CCl}_{4}$ intoxicated rats after treatment with low dose and high dose of alcoholic extract was $5.88 \pm 0.034 \mathrm{gm} / \mathrm{dl}$ and $5.87 \pm$ $0.025 \mathrm{gm} / \mathrm{dl}$ respectively.

Alkaline Phosphatase
The alkaline phosphatases are a family of zinc metaloenzymes, with a serine at the active centre, the highest concentration of alkaline phosphatase (ALP) are present in the cells of liver. Elevated levels of ALP in the blood are most commonly caused by liver diseases involving hepatic cellular injury (Kumar M., 2020). Thus the elevated levels of ALP in blood shows the probable damage to hepatic cells. In the present study post treatment with $\mathrm{CCl}_{4}$, the ALP level raised to $508.2 \pm 5.23 \mathrm{IU} / \mathrm{L}$ from $176.24 \pm 6.2 \mathrm{IU} / \mathrm{L}$ (control). This increase is a clear indication of liver damage induced by $\mathrm{CCl}_{4}$ toxicity in rats. When the $\mathrm{CCl}_{4}$ intoxicated rats were treated with the aqueous and alcoholic extract of Cuscuta reflexa, the ALP levels recovered (figure 3) i.e. $170.34 \pm 0.5$ $\mathrm{IU} / \mathrm{L}, 168.01 \pm 2.1 \mathrm{IU} / \mathrm{L}$ in low dose and high dose of aqueous extract of Cuscuta reflexa. In case of low dose and high dose of alcoholic extract of Cuscuta reflexa the ALP levels came to be $168.12 \pm 1.5 \mathrm{IU} / \mathrm{L}$ and $165.13 \pm 3.2 \mathrm{IU} / \mathrm{L}$. The data clearly shows the hepatoprotective activity of the aqueous and alcoholic extracts of Cuscuta reflexa.

Figure 3: Impacts of aqueous and alcoholic extract of Cuscuta reflexa on alkaline phosphate level of albino rats

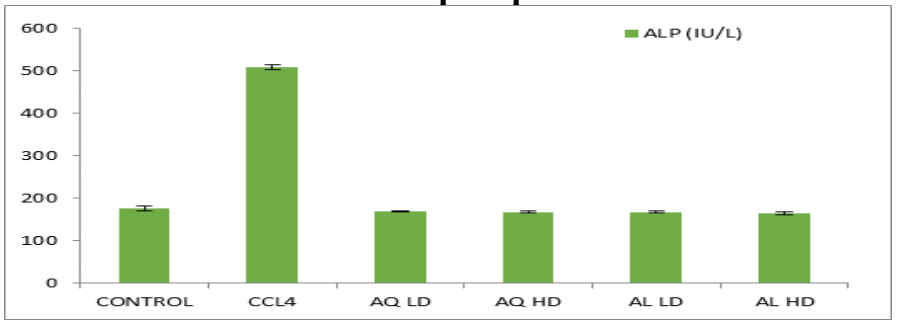

\section{Aspartate aminotransferase}

Aspartate aminotransferase (AST) exists in two isoenzymes namely mitochondrial and cytoplasmic form. It is found in highest concentration in the liver followed by heart, muscle, kidney, brain, pancreas and lungs. When the liver is damaged, it releases AST in the blood stream. Increase AST in blood may be an indication of liver damage (Kumar M., 2020). There was a significant elevation in AST levels in rats treated with $\mathrm{CCl}_{4}(107.2 \pm 4.25 \mathrm{IU} / \mathrm{L})$ as compared to the control $(52.3 \pm 2.36 \mathrm{IU} / \mathrm{L})$. The elevated levels decreased post treatment of $\mathrm{CCl}_{4}$ intoxicated rats with aqueous $(52.26 \pm$ $2.8 \mathrm{IU} / \mathrm{L}, 51.23 \pm 2.4 \mathrm{IU} / \mathrm{L})$ and alcoholic extract $(51.5 \pm 1.4$ $\mathrm{IU} / \mathrm{L}, 48.39 \pm 1.91 \mathrm{IU} / \mathrm{L})$ of Cuscuta reflexa. The results are graphically presented in figure 4 .

Figure 4: Impacts of aqueous and alcoholic extract of Cuscuta reflexa on Aspartate aminotransferase level of albino rats

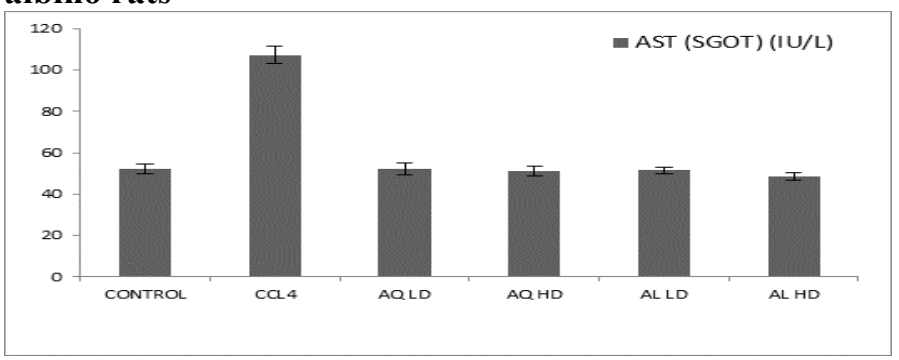




\section{Alanine aminotransferase}

The alanine aminotransferase (ALT) is an enzyme mainly found in liver, which makes its specific to assess liver damage. The body uses ALT to breakdown food into energy. Normally, ALT levels in the blood are low, if the liver is damaged, it will release more ALT in the blood. In the present study the ALT level increased from $146.63 \pm 1.2$ $\mathrm{IU} / \mathrm{L}$ (control) to $206.2 \pm 8.63 \mathrm{IU} / \mathrm{L}$ in $\mathrm{CCl}_{4}$ intoxicated rats. The ALT levels of $\mathrm{CCl}_{4}$ intoxicated rats recovered post treatment with aqueous and alcoholic extracts of Cuscuta reflexa. The results are graphically represented in figure 5 .

Figure 5: Impacts of aqueous and alcoholic extract of Cuscuta reflexa on total Alanine aminotransferase level of albino rats

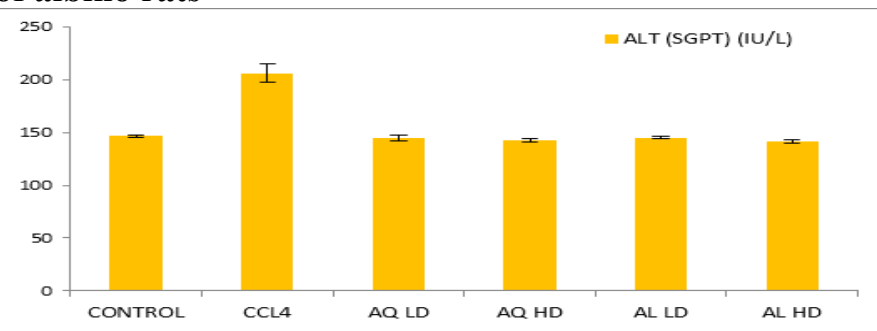

The results (figure $1-5$ ) clearly reveal the hepatoprotective activity of aqueous and alcoholic extract of Cuscuta reflexa. The phytochemical screening of aqueous and alcoholic extract of Cuscuta reflexa showed the presence of alkaloids, flavonoids, terpenoids, saponins, phenolics and tannins. The $\mathrm{CCl}_{4}$ treatment induced hepatotoxicity in rats, and the results clearly show the recovery of the rats from the induced hepatotoxicity. All the phytochemicals found in the preliminary screening have been known to have antioxidant properties. The phytochemicals are naturally occurring compounds in plant foods, have been reported to provide various biological functions in humans (12). Raj et al. (2010) (13) reported that the alkaloid fractions derived from Hygrophila auriculata leaves posed hepatoprotective activity against $\mathrm{CCl}_{4}$ induced toxicity in rats. Sawi and Sleem (2010) (14) concluded that the hepatoprotective activity of extracts of Senna surattensis may be due to the free radical scavenging activity posed due to the antioxidant activity of flavonoids present in the extract. The terpenoids (15), saponins (16), phenolics (17), tannins (18) have also been reported to possess antioxidant and hepatoprotective activity in plant extracts possessing them.

Thus on the basis of result of this study it is clear that the aqueous and alcoholic extract of Cuscuta reflexa show clear hepatoprotective activity against $\mathrm{CCl}_{4}$ induced toxicity in rats. This further indicates that the aqueous and alcoholic extracts and/or their derivatives may be used as potent hepatoprotective agent against liver related ailments.

Conflict of interests The authors declare that there is not conflict of interest.

Acknowledgements. The authors acknowledge the laboratory facilities extended by the Head, Department of Zoology, Ranchi University, Ranchi, and Jharkhand, INDIA.

\section{References:}

1. Pushpangadan, P. P. K. Iyenger and V. K. Damodaran. Role of traditional medicine in primary health care. Science for health 1995.

2. Kumari B., Sinha M. P. and Kumar M. Impact of aqueous fruit extracts of Haritaki (Terminalia chebula) on blood parameters of Mammalian model (Albino rats). Advances in Biological Research, 2016, 10(2): 106-109.

3. Tapsell, L. C., I. Hephil and L. Cobiac. Health benefits of herbs and spices, the past, the present, the future. Med. J., 2006, 185: 424.

4. Dar. R. A., Shahnawaz M. and Qazi P. H. General overview of medicinal plants: A review. The Journal of Phytopharmacology, 2017, 6(6): 349-351.

5. Lalchand, Sahu R., Rakshpal G. and Rout O. P. Cuscuta reflexa (Dodder plant): a critical review on the medicinal plant used in ayurveda. International Journal of Research in Ayurveda and Pharmacy, 2017, 8(6): 38-42.

6. Kumar M. and Sinha M. P. Green Nanotechnology: Synthesis of Silver Nanoparticles using aqueous leaf extract of Swertia chirayita. Notulae Scientia Biologicae, 2017, 9(3): 443 - 448.

7. Kumar M., Dandapat S. and Sinha M. P. Hepatoprotective activity of Punica granatum leaf extract against carbon tetrachloride induced hepatotoxicity in rats. Balneo Research Journal, 2018, 9(1): $24-27$.

8. Kumar M., Dandapat S. and Sinha M. P. Phytochemical analysis and Growth inhibitory impact of Swertia chirayita aqueous leaf extract against some human pathogens. World Journal of Zoology, 2015, 10(3): $188-190$.

9. OECD (Organisation for Economic Cooperation and Development) Guidelines for testing of chemicals/section 4: Health effects, Test No. 423; Acute Oral Toxicity - Acute Toxic class methods. 17th December, 2001

10. Kumar M., Synthesis, characterization of plant-mediated green nanoparticles and validation of medicinal impact on mammalian model. Unpublished Ph.D. Thesis submitted to Ranchi University, Ranchi. 2020, Supervisor - Prof. Manoranjan Prasad Sinha.

11. Kumar M., Dandapat S., Sinha M. P., Kumar A. and Raipat B. S. Different blood collection methods from rats: A review. Balneo Research Journal, 2017, 8(1): 46 - 50.

12. Yeum Kyung-Jin and Russel R. M. (2014). Biological functions of plant pigment phytochemicals in Humans. Systems Biology of Free Radicals and Antioxidants, Springer, Berlin, Heidelberg. ISBN 978-3642-30018-9

13. Raj V. P., Chandrasekhar R. H., Vijayan P., Dhanraj S. A., Mallikarjuna C. R., Venkata J. R. and Nitesh K. Indian Journal of Pharmacology, 2010, 42(2): 99 - 104.

14. Sawi S. A. and Sleem A. A. Flavonoids and hepatoprotective activity of leaves of Senna surattensis (Burm.f.) in CCl4 induced hepatotoxicityin rats. Australian Journal of Basic and Applied Sciences, 2010, 4(6): 1326-1334.

15. Wang C., Chen Y. and Hou C. Antioxidant and antibacterial activity of seven predominant terpenoids. International Journal of food properties, 2019, 22: $230-238$.

16. Chen Y., Miao Y., Huang L., Li J., Sun H., Zhao Y., Yang J. and Zhou W. Antioxidant activities of saponins extracted from Radix trichosanthis: an in vivo and in vitro evaluation. BMC complementary Medicine and Therapies, 2014, 14:86.

17. Pourreza N. Phenolic compounds as potential antioxidant. Jundishapur Journal of Natural Pharmaceutical Products, 2013, 8(4): 149-150.

18. Amarowicz . Tannins: The new natural antioxidants? European Journal of Lipid Science and Technology, 2007, 109(6): 549-551. 